\title{
Effect of cooling rates on T6 Treatment of B390 Aluminium-Silicon Hypereutectic alloys
}

\author{
Porawit Jiandon ${ }^{1}$, Sukangkana Talangkun ${ }^{1, a}$ \\ ${ }^{1}$ Department of Industrial Engineering, Faculty of Engineering, Khon Kaen University Thailand, 40002
}

\begin{abstract}
This research aimed to study an effect of cooling rates on T6 treatment process of B390 aluminium hypereutectic alloy. B390 casting samples were casted with pouring temperature of $710^{\circ} \mathrm{C}$ and solidified in three different cooling rates of $33.33,28.60$ and $22.22^{\circ} \mathrm{C} / \mathrm{s}$, respectively using three metal moulds. After that samples were subjected to $\mathrm{T} 6$ treatment: solution treated at $510^{\circ} \mathrm{C}$ for $30 \mathrm{~min}$ and aged at $200^{\circ} \mathrm{C}$ at various times. However, after ageing, hardness values of as-casted samples reduced with increasing cooling rate. It was found that the specimen cooled with the highest cooling rate exhibited the highest hardness. Peak hardness values of samples cooled with cooling rate of $33.33,28.60$ and $22.22^{\circ} \mathrm{C} / \mathrm{s}$ after ageing obtained from ageing time of 3,6 and 8 hour, respectively. Furthermore, the result showed that morphology of primary silicon, eutectic silicon and $\mathrm{Al}_{15}(\mathrm{Mn}, \mathrm{Fe})_{3} \mathrm{Si}_{2}$ phase presented in the aged specimen cooled with the highest cooling rate exhibited more globular, finer and distributed more evenly compared with the slower cooled samples. It can be concluded that rapid cooling rate increases concentration of $\alpha$-solid solution resulted in shorter aging time.
\end{abstract}

\section{Introduction}

Al-Si hypereutectic alloys are widely used for various applications due to its excellent properties. For examples; good castability, low coefficient of thermal expansion, and high strength to weight ratio. Al-Si alloys are normally casted by permanent mold casting, injection die casting and high pressure die casting (HPDC). B390 is one of the Al-Si hypereutectic alloy which is widely used in automotive applications. B390 has high strength and good wear resistance due to the present of primary Si phase. Generally, homogenously distribution of fine primary $\mathrm{Si}$ phase in the $\alpha$ phase of Al-Si Hypereutectic alloys are required. The major factor affecting size and morphology of the primary Si phase is cooling rate [1]. Because, casting cooling rate determines grain size, secondary dendrite arm spacing (SDAS), vacancies and the distribution of intermetallic compounds [2-3]. In addition, the mechanical properties of B390 are strongly influenced by the local microstructural morphology that formed during solidification [4-5]. Furthermore, the solidification rate determines the cooling rate which also has an effect on microstructure and mechanical properties of castings $[6,7,8]$.

However, most of the B390 workpieces after casting must be undergone $\mathrm{T} 6$ heat treatment process to enhance mechanical properties $[2,9,10,11]$. Many researchers found that slightly different cooling rates had an effect on the holding time in the solid solution treatment, which greatly affects the formation of precipitates on the subsequent aging process [2, 12]. Therefore, the main objective of this research was to study the influence of the cooling rate on the morphology and hardness of B390 after T6 heat treatment process.

\section{Experimental method}

B390 Aluminium alloy was supplied as ingots from DAIKI Aluminium Industry (Thailand). The chemical composition of the B390 was analysed using the optical emission spectrometer (ARL 3460 OE Spectrometer). The result showed composition of the $\mathrm{B} 390$ balance $\mathrm{Al}$, $18.3 \mathrm{wt} \% \mathrm{Si}, \quad 0.9 \mathrm{wt} \% \mathrm{Fe}, \quad 4.8 \mathrm{wt} \% \mathrm{Cu}, \quad 0.3 \mathrm{wt} \% \mathrm{Mn}$, $0.5 \mathrm{wt} \% \mathrm{Mg}, \quad 0.5 \mathrm{wt} \% \mathrm{Zn}$ and $0.06 \mathrm{wt} \% \mathrm{Ni}$. The received alloy conformed to Aluminium Association Standard (AA) [13].

An alumina crucible was used for melting. The specimen was casted in a shape of a cylinder with length of $150 \mathrm{~mm}$ and diameter of $15 \mathrm{~mm}$. The metal mould A, B and $\mathrm{C}$ used in this experiment was showed in fig. 1 . The three different mould geometries was showed in Table 1. The upper mould and the lower mould were assembled together using nuts and bolts. The cooling curve of the specimen was determined from temperature-time data. The temperature of the casting during the solidification

\footnotetext{
${ }^{\mathrm{a}}$ Corresponding author: sukangkana@kku.ac.th
} 
process were monitored by three thermocouples positioned at the upper, center and lower parts of the cast.

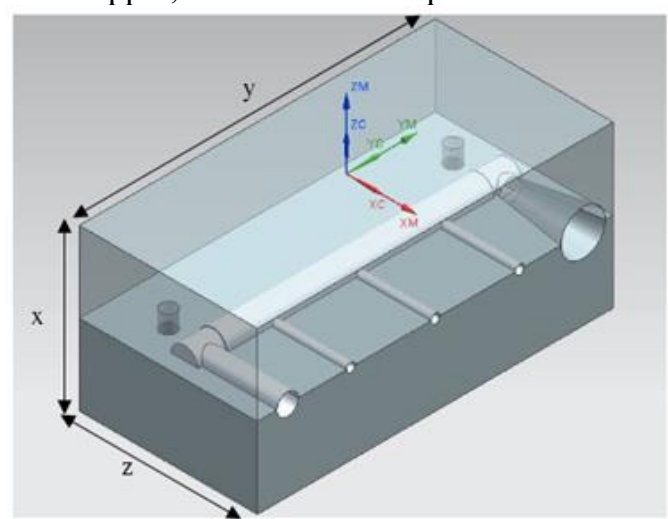

Figure 1. The metal mould

Table 1. Dimensions of moulds

\begin{tabular}{|c|c|c|c|}
\hline Mould & $\begin{array}{c}\text { Width, X } \\
(\mathrm{mm})\end{array}$ & $\begin{array}{c}\text { Length, Y } \\
(\mathrm{mm})\end{array}$ & $\begin{array}{c}\text { Thickness, } \\
\mathrm{Z}(\mathrm{mm})\end{array}$ \\
\hline A & 140 & 200 & 190 \\
\hline B & 120 & 200 & 140 \\
\hline C & 100 & 200 & 90 \\
\hline
\end{tabular}

The experimental procedure was as follows: (1) B390 alloy was melted in an alumina crucible by induction furnace; (2) three K-type thermocouples were inserted in the mould cavity and temperature data was collected via a data logger model CMC-99; (3) Pouring the molten alloy to the preheated mould (approximately $150^{\circ} \mathrm{C}$ ) the pouring temperature was approximately $710^{\circ} \mathrm{C}$; (4) After cooling in a metal mould at ambient temperature, all samples were subjected to solution treatment at $510^{\circ} \mathrm{C}$ for $30 \mathrm{~min}$ followed by water quenching; (6) finally, artificial aging was performed at $200^{\circ} \mathrm{C}$ for $1-10 \mathrm{~h}$.

\section{Results and Discussion}

\subsection{Cooling rate of casting in metal mould}

Total solidification time obtained from mold A, B and C were 6,7 and 9 seconds respectively. The average cooling rate was determined from a slope of a cooling curve from $710^{\circ} \mathrm{C}$ to $510^{\circ} \mathrm{C}$ (i.e. a pouring temperature to a solidus temperature). The cooling rate of mold $\mathrm{A}, \mathrm{B}$ and $\mathrm{C}$ was $33.33,28.60$ and $22.22^{\circ} \mathrm{C} / \mathrm{s}$, respectively. The greater mould thickness showed higher cooling rate. This was due to the greater temperature difference between inner and outer surfaces $(\Delta T)$ of the mould, resulting in greater heat transfer rates [14-15].

\subsection{Microstructure analysis}

As-cast condition, the microstructures in cross section area of the cast B390 are showed in Fig. 2. In as casted condition, by comparing shape of intermetallic phase with Backerud et al., (1990) [16] and Tillová et al., (2012) [17]. Microstructure consists of $\alpha$-Al phase, primary $\mathrm{Si}$ and eutectic phase. All conditions revealed a uniform distribution of primary $\mathrm{Si}$ in the aluminium alloy matrix. It should be noted that decrease in cooling rate resulted in increasing grain size of $\alpha-\mathrm{Al}$ phase and size of primary $\mathrm{Si}$ intermetallic phase such as $\mathrm{Al}_{15}(\mathrm{Mn}, \mathrm{Fe})_{3} \mathrm{Si}_{2}$ phase, $\mathrm{Al}_{2} \mathrm{Cu}$ phase, $\mathrm{Al}_{5} \mathrm{FeSi}$ phase and $\mathrm{Al}_{5} \mathrm{Mg}_{8} \mathrm{Cu}_{2} \mathrm{Si}_{6}$ phase [18].

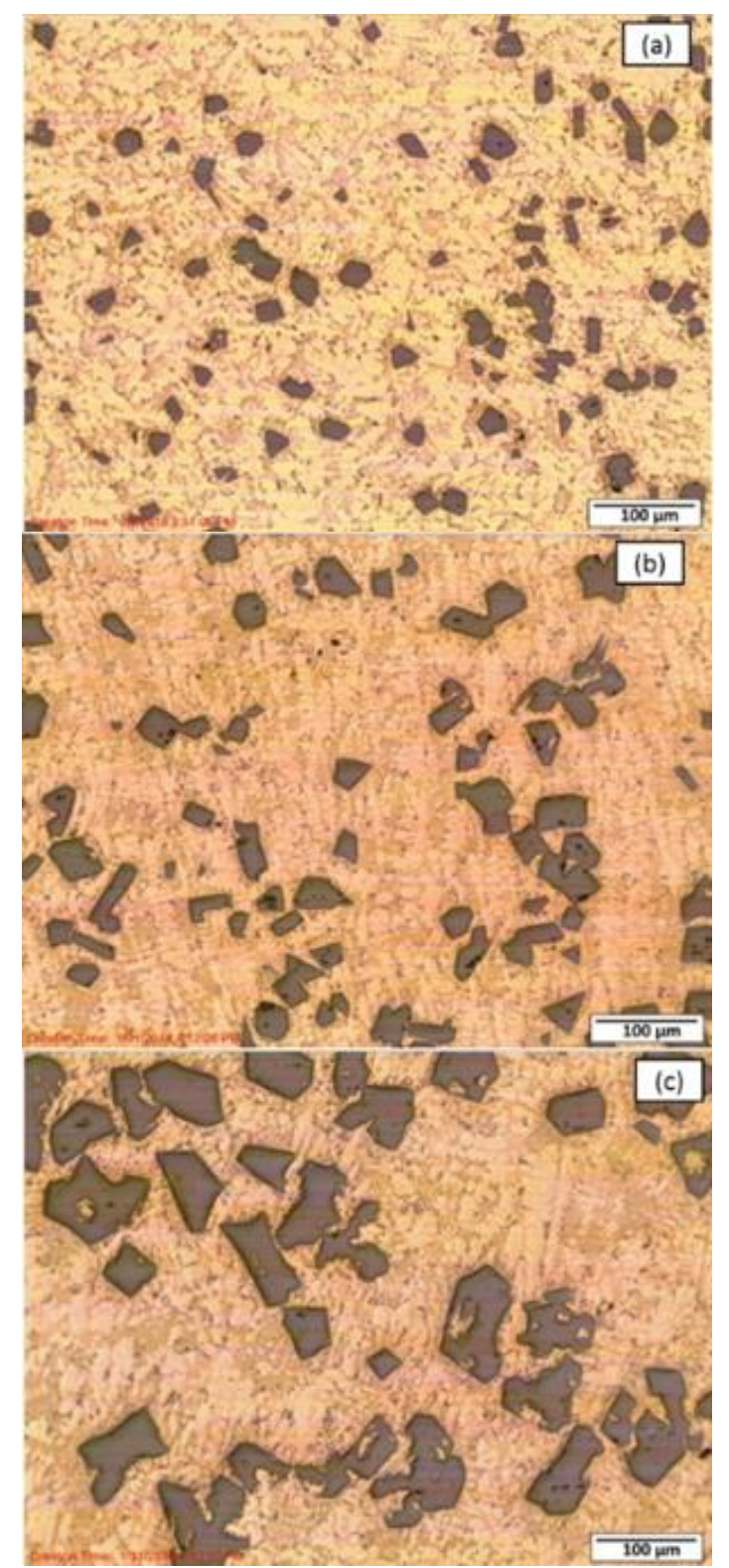

Figure 2. Microstructures of As-cast B390 at different cooling rates. (a) $33.33^{\circ} \mathrm{C} / \mathrm{s}$, (b) $28.60^{\circ} \mathrm{C} / \mathrm{s}$ and (c) $22.22^{\circ} \mathrm{C} / \mathrm{s}$

The microstructures in cross section area of the B390 after T6 at aged point are showed in Fig. 3. It can be seen that the highest cooling rate specimen exhibited the most uniform distribution of primary $\mathrm{Si}$, eutectic silicon and 
intermetallic phases. It should also be noted that after T6, primary $\mathrm{Si}$ also became finer and homogenously. However, when ageing time increased, these fine primary silicon and fine eutectic growth to large and irregular shape.

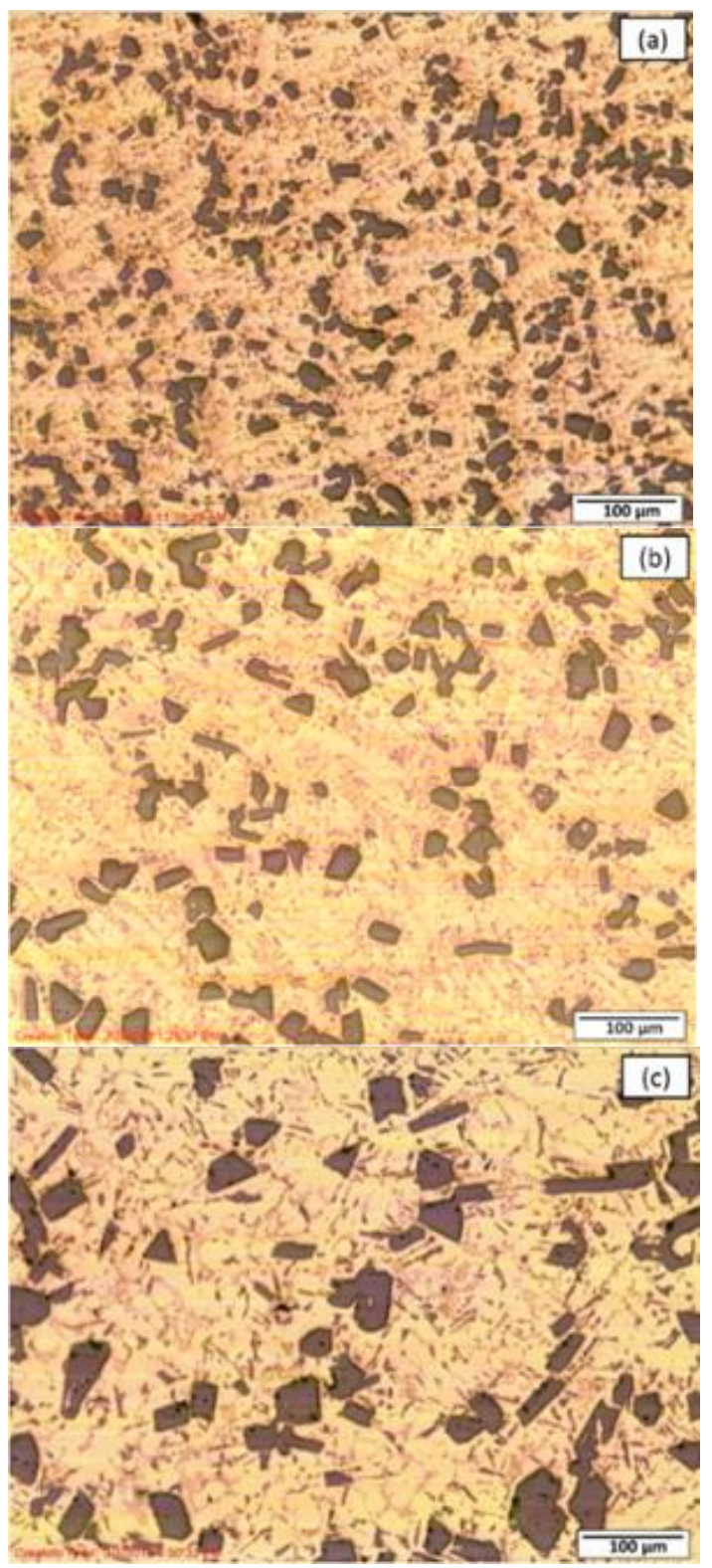

Figure 3. Microstructures of $\mathrm{B} 390$ at maximum hardness (aged condition) after $\mathrm{T} 6$ of different cooling rate samples. (a) $33.33^{\circ} \mathrm{C} / \mathrm{s}$, (b) $28.60^{\circ} \mathrm{C} / \mathrm{s}$ and (c) $22.22^{\circ} \mathrm{C} / \mathrm{s}$

Fig. 4 and 5. SEM images showed morphology of B390 in as-casted and $\mathrm{T} 6$ conditions. It indicated that $\mathrm{Al}_{2} \mathrm{Cu}$ and Chinese script- $\left.\left.\mathrm{Al}_{15}\right) \mathrm{Mn}, \mathrm{Fe}\right)_{3} \mathrm{Si}_{2}$ presented in all samples. In $\mathrm{T} 6$ condition, the specimen cooled with the highest cooling rate, intermetallic compounds exhibited more globular, finer and evenly distributed. At slower cooling rate, Fe-rich intermetallic phase remained after T6. This may a result of non-fully dissolved during solution treatment. Large particles may not fully dissolve in solution treatment in an experiment of $30 \mathrm{~min}$. The primary $\mathrm{Si}$, eutectic phase and $\left.\left.\mathrm{Al}_{15}\right) \mathrm{Mn}, \mathrm{Fe}\right)_{3} \mathrm{Si}_{2}$ exhibited more globular, finer and evenly distributed increases strength [18-19].

The dissolution of intermetallic phase of B390 in this experiment showed in a good agreement with works of Manasijevic et al., (2013) and Yu, Zhao et al., (2017), that rapid cooled $\mathrm{Al}-\mathrm{Si}$ Hypereutectic exhibited fine $\mathrm{Al}_{2} \mathrm{Cu}$ phase and $\left.\left.\mathrm{Al}_{15}\right) \mathrm{Mn}, \mathrm{Fe}\right)_{3} \mathrm{Si}_{2}$ in casting. Fine particle has greater dissolution rate during solution treated [20-21].
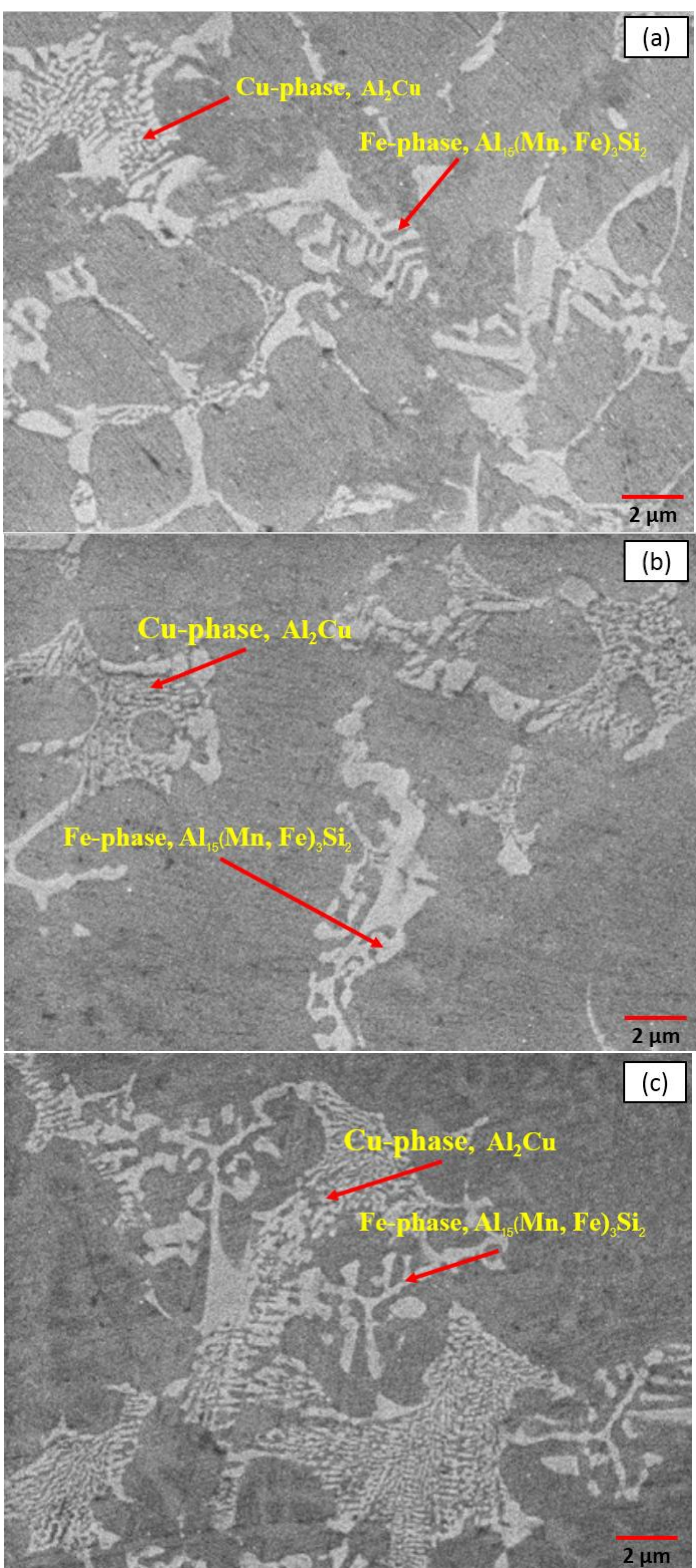

Figure 4. SEM Micrographs at different cooling rate on As-cast. (a) $33.33^{\circ} \mathrm{C} / \mathrm{s}$, (b) $28.60^{\circ} \mathrm{C} / \mathrm{s}$ and (c) $22.22^{\circ} \mathrm{C} / \mathrm{s}$ 

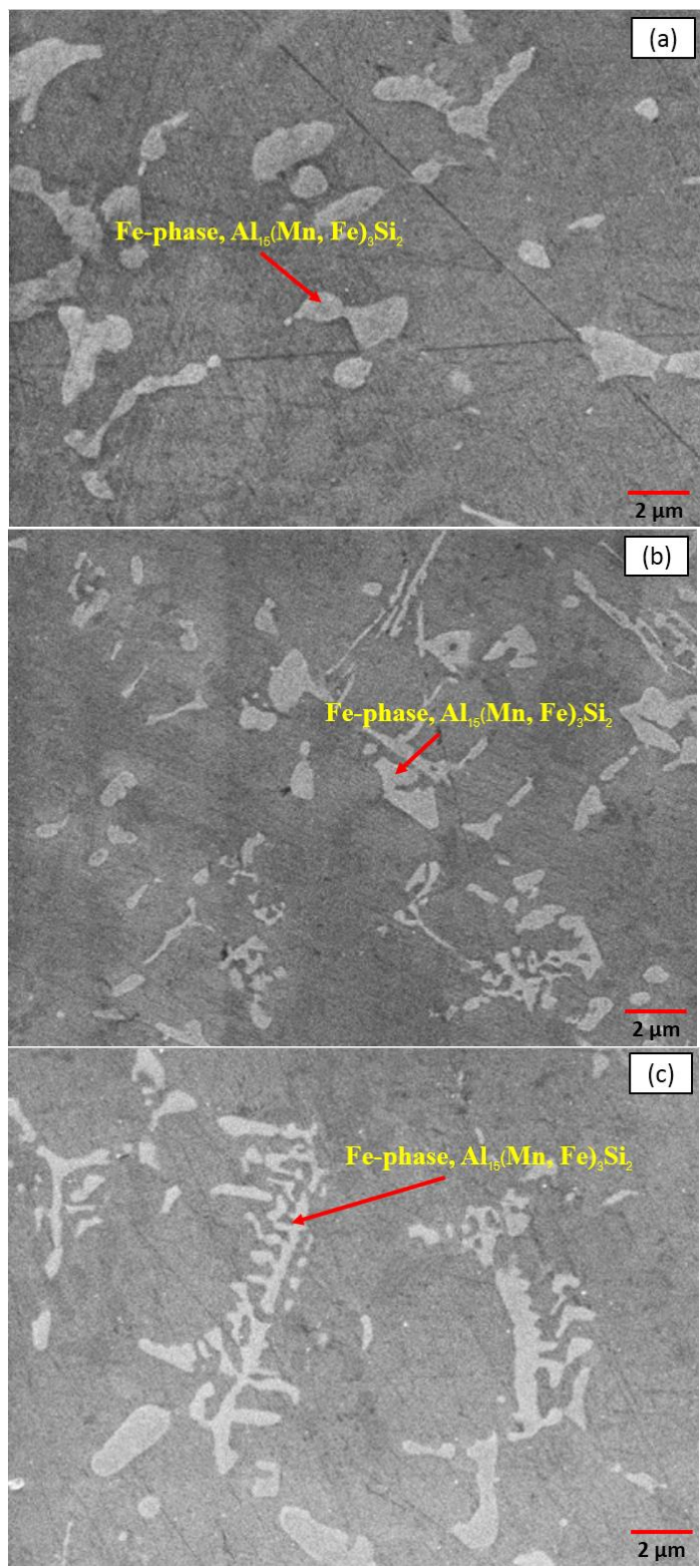

Figure 5. SEM Micrographs at different cooling rate on T6 (Aged). (a) $33.33^{\circ} \mathrm{C} / \mathrm{s}$, (b) $28.60^{\circ} \mathrm{C} / \mathrm{s}$ and (c) $22.22^{\circ} \mathrm{C} / \mathrm{s}$

\subsection{Influence of cooling rate on hardness}

Fig. 6 shows the hardness after ageing. Hardness values of as-casted samples which cooling rate of 33.33, 28.60 and $22.22^{\circ} \mathrm{C} / \mathrm{s}$ were $75.07,76.50$ and $78.24 \mathrm{HRB}$, respectively. Decrease in cooling rate increased size of hard intermetallic compounds and second phases resulted in greater hardness. After T6, hardness of all samples was increased. It was found that the specimen cooled with the highest cooling rate exhibited the highest hardness of 95.77 HRB. Peak hardness values of samples cooled with $33.33,28.60$ and $22.22^{\circ} \mathrm{C} / \mathrm{s}$ after ageing obtained from ageing time of 3, 6 and 8 hour, respectively. The highest cooling rate specimen reached the maximum hardness only in 3 hour of ageing time which is the shortest ageing time. This result conforms with the work of Lang et al., (2011) suggested that precipitation of $\mathrm{Al}-\mathrm{Mg}-\mathrm{Si}-\mathrm{Cu}$ on artificial aging of the highest cooling rate sample exhibited shortest ageing time. This was due to the rapid cooling rate induced the greater number of GP-zone resulted in rapid precipitation formation [12]. After peak aged, hardness of samples was reduced. this was a result of the size of the second phase particles increased coupled with the amount of the second phase particles decreased with ageing time resulted in the lower effect of precipitation hardening.

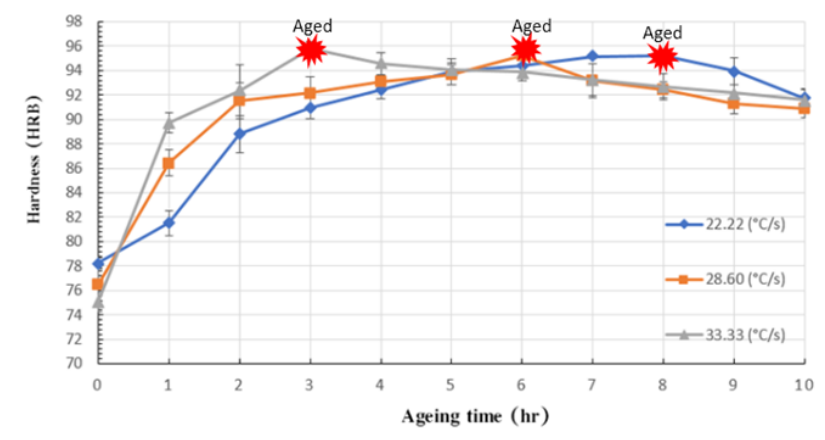

Figure 6. Average hardness at different cooling rate on As-cast and T6 (Aged)

\section{Conclusion}

The following conclusions were derived from the research work.

1) Cooling rate has an influence on microstructure and hardness of B390 casting. Increase in cooling rate result in size reduction of primary $\mathrm{Si}$, eutectic silicon and intermetallic phase. In addition. Rapid cooling improved the distribution of the second phases in the alloy. It should be noted that slow cooled sample exhibited larger intermetallic phases resulted in greater hardness.

2) In T6 condition, the rapid cooling rate increased spheroidization, distribution of the primary silicon, eutectic silicon, and $\mathrm{Al}_{15}(\mathrm{Mn}, \mathrm{Fe})_{3} \mathrm{Si}_{2}$ phase. After solution treatment, $\mathrm{Al}_{2} \mathrm{Cu}$ phase has not been observed in SEM images.

3) Increase in cooling rates of casting resulted in fine and evenly distribution of eutectic and second phases which contributed to greater concentration of the solid solution condition. This result in shorter holding time to reach the maximum hardness in ageing.

\section{Acknowledgement}

Authors would like to thank supply chain and logistics system research unit (SCLS) Khon Kaen University (KKU) Thailand for supporting research grant.

\section{References}

1. J. Pavlovic-Krstic, R. Bähr, G. Krstic, and S. Putic, AMES, 15 (2009)

2. S.E. Maube, D.N. Wang'ombe, S.M. Maranga, and J.M. Kihiu, JSRE, 1 (2014) 
3. R. Chen, Y. Shi, Q. Xu, and B. Liu, Trans. Nonferrous Met. Soc. China, 24 (2014)

4. L. Hou, Y. Cai, H. Cui, and J. Zhang, Int. J. Min. Met. Mater, 17 (2010)

5. Z. D. Kadhim, Journal of Engineering 17 (2011)

6. L.Y. Zhang, B. D. Zhou, and Z. J. Zhan, Mat. Sci. Eng. A-Struct, 1 (2007)

7. L.A. Dbrzanski, R. Manaira, and J. Sokolowski, J. Mater. Process. Tech, 191 (2007)

8. J. Hemanth, Materials and Design, 21 (1999)

9. A.M.A. Mohamed and F.H. Samuel, INTECH (2012)

10. W. Kasprzak, J.H. Sokolowski, H. Yamagata and H. Kurita, Heat Treating: Proceedings of the 25th ASM Heat Treating Society Conference, (Indianapolis in USA, 2009)

11. W. Kasprzak, H. Kurita, G. Birsan and B. S. Amirkhiz, Materials and Design, 103 (2016)

12. P. Lang, A. Falahati, M.R. Ahmadi, P. Warczok, E. Povoden-Karadeniz, E. Kozeschnik and R. Radis, MS\&T, (2011)
13. NADCA Product Specification Standards for Die Castings, (2015)

14. K.C. Bala, R. H. Khan, LJS, 25 (2014)

15. J.M. Lee, K.H. Kim, H.J. Kim, Y.S. Ahn, JILM, (2010)

16. L. Backerud, G. Chai and J. Tamminen, Solidification Characteristics of Aluminum Alloys, 2 (1990)

17. E. Tillová, M. Chalupová, and L. Hurtalová, InTech, (2012)

18. Xu. C.L., Jiang. Q. C. J: Mater. Sci. Eng. A, 437 (2006)

19. T. Jaglinsk, ASME, 126 (2004)

20. S. Manasijevic, S. Markovic, Z. A. Pavlovic, K. Raic and R. Radica, MIT, 47 (2013)

21. W. Yu, H. Zhao, L. Wang, Z. Guo and S. Xiong, J. Alloys Compd, 731 (2017) 